Kyung Hyun Kim and CedarBough Saeji ${ }^{1}$

\title{
Introduction: A Short History of Afro-Korean Music and Identity
}

\begin{abstract}
Kyung Hyun Kim currently serves as a professor in the Department of East Asian Studies and Visual Studies, UC Irvine. He is a novelist, a scholar and a film producer. Prof. Kim is author of The Remasculinization of Korean Cinema (2004), Virtual Hallyu: Korean Cinema of the Global Era (2011), Hegemonic Mimicry: Korean Popular Culture of the 21st Century (2021), all published by Duke University Press, and a Korean-language novel entitled In Search of Lost G (Ireo beorin G-rul chajaso, 2014).
\end{abstract}

CedarBough T. Saeji, currently a Visiting Assistant Professor at Indiana University, is a scholar of Korean performance who approaches issues from gender to cultural policy through examining everything from traditional mask dance dramas to the latest K-pop hits.

\author{
East Asian Studies \\ University of California \\ Irvine, CA 92697-6000 \\ USA \\ kyunghk@uci.edu
}

East Asian Languages and Cultures Indiana University - Bloomington $355 \mathrm{~N}$ Jordan Ave Bloomington, IN 47405

USA

c.saeji@gmail.com

In July 1971 fifty black soldiers from Camp Humphreys destroyed several bars in the camp town located next to the base in Anjeong-ni, Pyeongtaek, in frustrated protest that the establishments were racially segregated. The Korean National Police and the American Military Police (MP) were called in to break up the conflict between black GIs and the Korean villagers who were angry at damage to their establishments. Some Koreans were rumored to have been killed during the "race riot" aimed at desegregating the camp town. A black American soldier was severely injured and several Koreans were reportedly stabbed-prompting the MPs to use tear gas grenades to disperse the angry Korean mob. (Freeland and Lea 1971)

1. This work was supported by the Core University Program for Korean Studies through the Ministry of Education of the Republic of the Korea and Korean Studies Promotion Service of the Academy of Korean Studies (AKS-2016-OLU-2250005). The editors would like to thank the Academy of Korean Studies and Hyundai Motors America that supported the Afro-Korean Hip-Hop Festival and Conference held at the University of California-Irvine where all of the papers were presented on 7 October 2019.

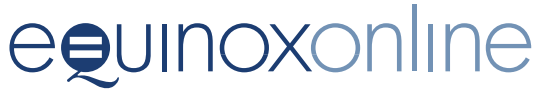




\section{A Long and Complex History of Race Relations}

Though the tension between Korean business owners in America and African Americans during the 1992 Los Angeles riots and more recently post-George Floyd protests have grabbed the mainstream media's attention, Koreans have been awkwardly caught between populations of white Americans and African Americans since the era of civil rights protests. Though blacks-only platoons were phased out during the Korea War (1950-53) by President Harry Truman, racial discrimination and segregation remained entrenched in barracks and in social life during the US military occupation of Korea throughout the latter part of the twentieth century. ${ }^{2}$ Camptown clubs for US military personnel in Korea were segregated-so much so that the violent protest described above broke out in 1971 motivated by black GIs upset by the de facto policies of segregation enacted by these clubs and their proprietors. It was Korean businesses that separated entertainers and sex workers who serviced white soldiers from those who serviced their black counterparts. More than two decades after the American military had desegregated, the racial tensions and disparities on US military bases continued, and extended to the nearby clubs and the music that they played. Desegregation was officially enacted by requiring music to be played for both black and white patrons. As stated by Capt. A. D. Malloy, who was then responsible for easing the racial tensions in the American military bases in Korea and headed the committee called GIT (Get It Together), "We check on the variety of music played in the clubs. They must mix it up; some soul, some rock, some country and western. If they don't mix the music, you get ... segregation" (Lea and Brown 1971: 12). In contrast to these official efforts to ease tensions, Korean bar owners refused to serve African American soldiers or play the music of their preference out of fear of retribution from white soldiers.

It would be unethical to find Korean female employees and proprietors of the Korean bars culpable for the escalation of American racial tensions that were being played out in Korea at the time. US military officials could have purchased these clubs and managed them on their own. However, the American military's acquiescence in the technically illegal but quietly permitted sex work arranged in these clubs largely steered it away from taking such measures. Korean bar owners and entertainers were thus left with a

2. President Harry S. Truman signed Executive Order 9981 in 1948, which abolished discrimination "on the basis of race, color, religion, or national origin" in the United States Armed Forces. The Korean War was the first war that tried to phase out all-black units in the US military. However, many personnel in the military refused to desegregate the army, and the last of the all-black units in the United States military was terminated in 1954-one year after the cease-fire agreement was signed in Korea (Bauer 1948). 
problem too hot to handle on their own, becoming casualties without agency in another country's race war. Korean proprietors found themselves awkwardly caught between white establishment power and black anger, just like the 2,200 Korean American business owners who suffered heavily from damages incurred during the Saigu event that took place in Los Angeles in 1992 after four white officers were acquitted in the beating of Rodney King. ${ }^{3}$

In the year 2020, exactly seventy years after the war broke out in Korea, much has changed. Music, figuratively speaking, has ceased to play on the jukebox, and is instead listened to via social media-driven streaming apps. In America, listeners using new online jukeboxes such as YouTube, Spotify and Apple Music may choose to hear Korean idols whose music is composed and produced by pop artists influenced by a diverse selection of 1970s American music-including country, rock, funk, soul, disco and even Latin beats. Korean minjok (national ethnic) identity, which has long been situated awkwardly between white and black, often as an anxious bystander, has emerged as an active global leader in health, tech innovation and manufacturing and in the past few years has claimed a strong stake in global popular culture as well. Koreans are no longer meekly forced to the sidelines to cautiously push the buttons on an American playlist preselected along colour lines or learn songs whose meaning and historical background are foreign to them.

\section{Koreanness, Ethnicity and Camptown Performances}

Literary theorist Lee Jin-kyung expertly articulates how "Koreanness [has] begun to be delinked from its exclusive attachment to ethnicity" (Lee 2010: 19). But this process has taken place only after a lengthy period in the twentieth century during which Korean minjok was almost exclusively aligned with the ethnic differentiation of the Korean people under Japanese colonial rule and then over its reassertion during the subsequent decades. Now that two per cent of Korea's population is foreign born, and the children of married migrants are becoming a substantial segment of the school-aged population, Korea is, of necessity, rethinking what it means to be Korean. As Lee also argued, "South Korea as a nation-state must now operate transnationally, across national borders" (Lee 2010: 21). The term han-minjok (the term han is derived from both one and country, and Koreans call their country Han-guk or han + nation) has always insisted on blurring the boundary between the common blood ethnicity and the national citizenship that represents Korea. ${ }^{4}$

3. For a deeper dive into the 1992 LA riots through the lens of Korea, see Kim (2008) and Yoon (2007). A quick summary can be found in Constante (2017).

4. Henry Em notes that the Japanese pronunciation of the "compound minzoku (K: minjok), understood as ethnic nation, began to circulate in Korea in the early 1900s". This

\section{e是Uinoxonlıne}


However, the continued currency of this term has been threatened by recent reconsideration of the non-ethnocentric designations that must be given to the terms of citizenship in order to include non-Korean ethnic migrant settlements and the country's expanding transnational cultural and economic activities.

In her examination of post-Korean War literature, Lee has employed Foucault's concept of biopolitics, as well as Mbembe's necropolitics, and brought them to bear on the precarious and disposable labour of Korean sex workers in US camptowns throughout the post-war years. ${ }^{5}$ Lee defines the three working-class labour contexts (Korean military labour in Vietnam, Korean military prostitution for the US, and Asian migrant labour in contemporary South Korea) of what she calls the "transnational proletarianization of race" (2010: 15), arguing that these labours have constituted the "most disposable (labor) commodities" (2010: 7).

Missing from Lee's analysis, however, is a discussion of the extensive entertainment labour produced by Korea throughout the latter part of the twentieth century for a live audience of American soldiers. Because some of the entertainment labour devoted to the US military overlapped with employment in Korean broadcasting companies and clubs, it is difficult to estimate precisely how many performers were employed in Korea by the US military at any given time. However, as early as the late 1950s, the demand for Korean performers in American military clubs was so high that several Korean talent agencies began operations-each employing hundreds of singers and musicians to train for the auditions held at the main American base in Yongsan (Maliangkay 2006: 23; see also Yi 2005). Trained and auditioned before American military judges, these performers would come to constitute the critical labour base for the entire Korean popular music industry in the years to come. However, the US military treated them as disposable and stories of dire working conditions make clear that, for some, performing was not much better than sex work. ${ }^{6}$

However, one significant distinction has to be made between these two conspicuous service labour sectors that emerged from the US military base

was well after the neologism of minzoku began to circulate in Japan following Miyazaki Muryu's translation of "French Assemblée Nationale as minzoku kaigi" (Em 2013: 67).

5. In addition to Lee's excellent research on sex work in Korea, the topic of sex work for the US military in Korea has also been explored by Cheng (2010), Cho (2008), Lee (2018), Park (2019) and Lie (1995), among others.

6. The hit Korean movie Ji-ok Hwa (1958, dir. Shin Sang-ok) depicts camp town life and entertainment for the US military-https://www.youtube.com/watch?v=4FU1Hc7Zk24. See also the astute analysis by Maliangkay (2011). 
camp areas in Korea: unlike female sex workers, whom Lee associates with "necropolitical labor" or the "extraction of labor from those 'condemned' to death, whereby the fostering of life, already premised on their death or the disposability of their lives, is limited to servicing the demands of the state or empire" (2010: 6), some of these musical performers were able to move forward in their lives and careers, preventing their own labour from becoming disposable by seeking out musical and artistic innovations that led to their becoming the biggest names in Korean show-biz after retiring from their American sho-dan careers. Put another way, although these Korean entertainers could have been merely live jukeboxes reproducing the hits they were instructed to sing, and disposed of as mass media grew to replace the need for extensive live programming, instead they emerged from these post-war ashes to sow the seeds for authentic acts on some of the most prominent stages in the world, incubating an exciting hybrid form of twenty-first-century cultural identity. The demand for Koreans to produce an endless supply chain of disposable, entertainment bodies regulated by American hegemony would, in the last decade of the twentieth century, become remediated, re-ethnonationalized into a new, cool Korean-ness, one that would prepare itself for the transnational, cosmopolitan sense of hallyu (the international spread of Korean popular culture) located between the essential and the disposable, between white and black, and between Korean and American.

Although Lee's characterization of Korean service labour for the American military as disposable and necropolitical labour is undoubtedly persuasive, we would also suggest that absent from this model is the possibility that many of these forms of sex service labour resisted condemnation to death and ended up reviving and reproducing-begetting life. Some of the best-known Korean American bi-racial star athletes and singers, ranging from former NFL star Hines Ward to R\&B diva Insooni, have African American fathers and Korean mothers who first met in US military camptowns in Korea. Although it should not be speculated that these stars' mothers were sex workers, lack of paternal support complicated their childhoods, suggesting that on some level their mothers' lives were construed as “disposable”. However, the successful lives not only of these stars but also those of many more offspring reared by Korean mothers and American military servicemen throughout the twentieth century are testaments to a (re-)productive labour on the part of Korean sex workers, which extended well beyond a condition of disposability and necropolitics in the US military throughout the twentieth century.

\section{e是Uinoxonlıne}




\section{Toward the Present Day}

Throughout the 1950s and 1960s, hundreds of stages on US military bases introduced thousands of Korean live performers, ${ }^{7}$ all of whom were expected to sing American hits in English. Simultaneously, the musical influences emanating from these military venues were permeating the Korean performance environment. Artists such as Sin Junghyeon (Shin Joonghyun) took the music and reimagined it with Korean elements and in the Korean language. Sin Junghyeon himself became a key influence in making rock mainstream in Korea ${ }^{8}$-his wife Myeong Jeonggang was also a former sho-dan performer. By the late 1980s his time on stage was drawing to a close, but he continued to exert his influence as a music club owner, in the songs he wrote for diva Kim Wanseon (trained by yet another sho-dan singer, her aunt Han Baekhui), and through the legacy of one of his sons, Sin Daecheol. Sin Daecheol, a guitar virtuoso like his father, helped discover and develop the talent of a young high school dropout named Seo Taiji, who joined his band Sinawe. ${ }^{9}$ Although various songs containing rap and hip hop elements had been performed before 1992, it was Seo Taiji (as frontman of Seo Taiji and Boys) who served as the crucial link in popularizing hip hop among Korean audiences. Seo has continued to be an on-again off-again pivotal figure in Korean music, collaborating with artists such as IU and BTS in recent years, and both of the "Boys", Lee Juno and Yang Hyunseok (founder of YG Entertainment), have also left a prodigious mark on the entertainment scene. We provide this history to demonstrate the many ways that musical performances for the US military have served as an important foundation for the Korean music industry.

After Seo Taiji and Boys, hip hop continued to grow in importance in the Korean musical scene, and today most mainstream idol K-pop groups include one or more members who rap. Well-known artists such as Zico, formerly of idol group Block B (see Im Jae-hyun's article, this issue), seek to be understood as authentic practitioners of hip hop despite their massive fame, while artists in a collective like OSIXTWO (see Amos Farooqi's article) or solo artists like Sleeq (see Kim Iljung's article), struggle to be noticed at all while being guided by concerns larger than themselves such as regional representation or feminism. As a matter of fact, the thoughtfulness of the lyrics and the considered self-presentations of hip hop artists profiled in this special issue demonstrate

7. The performances for the American soldiers continue to this day. However, as personalized media options expanded over time, the demand for live performances in Korea tapered off.

8. See Shin Hyunjoon and Kim Pilho's chapter on the influence of Sin (Shin and Kim 2014).

9. See Maliangkay (2014) for more on Seo Taiji. 
an important difference between them and artists of the more internationally known idol pop industry, where commercial concerns and agency power generally overwhelm the social stances of individual artists.

The articles in this special issue came about thanks to a unique academic conference that was quite possibly the first ever cultural and academic event celebrating Afro-Korean identity hosted by a Korean studies centre. "Korean Hip Hop and New Explorations of Afro-Korean Identity" was held at UC Irvine on 7 October 2019, but was conceived and discussed more than a year earlier. Both organizers viewed the lack of academic work on Korean hip hop as a substantial weakness in the broader literature on Korean music. The conference was conceptualized as an opportunity for a conversation that explicitly understood Korean hip hop's debt to African American hip hop-as subsequently reflected in the remarks from keynote speaker Adam Bradley of the University of Colorado Boulder (and the RAP Lab) and the historical accounts of the early days of hip hop shared by American great Kurtis Blow-while also recognizing and explicating the particularities of the Korean scene. A full day of presentations of academic research was supplemented by an engaging question and answer session with Korean hip hop legend Tiger JK, his label mate Bizzy, and Kurtis Blow. The day ended with a sold-out concert featuring an opening act by Diverseddie followed by performances from Kurtis Blow and MFBTY, a group composed of Tiger JK, Yoonmirae and Bizzy.

During the concert, Yoonmirae, who is prominently featured in several articles in this volume, announced to her audience that she is proud to be "half-black and half-Korean". Although Yoonmirae-performing with her Korean husband Tiger JK-was referring to her ethnic background, undoubtedly her music must also be recognized as "half-black and half-Korean", and we, as guest editors of this issue of the Journal of World Popular Music, have learned not to digress from this central issue that merits treatment in a special volume on Korean hip hop. Not only is hip hop strongly associated with African American identity, which, despite the uneasiness and even denial of many Koreans, penetrates deep into the soul of Korean popular music, but it is also one of the only types of popular music in which the singer-songwriter tradition continues.

The storyteller-performer who creates poetry based on real autobiographical material-such as his or her name, ethnic identity, past illnesses, bodily art and other life experiences-sits at the centre of the hip hop world in Korea, and the artists whose work is analysed in the articles in this issue demonstrate the ways that rapping in Korean or making music in Korea creates its own series of unique challenges. Sociologist Robert Hamilton's article directly addresses blackness and race in Korea and its hip hop music, exploring rap "as a space of racial representation aimed at exposing the effects of K-rappers'

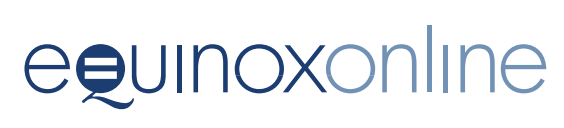


silence on anti-heug-in sentiment in South Korea". Hamilton focuses his argument on the classic hip hop group Garion while calling for Korean hip hop artists to use their cultural leadership to address race in Korea. Music theorist Jinny Park's article also brings Garion (among others) into focus, as she examines an important technical difficulty: rhyme in a language where end rhyme is ridiculously easy (in Korean the verb is placed at the end of the sentence, and conjugation-which is identical for all sentences conjugated in the same way-falls at the end of the verb). Park demonstrates the evolution of rhyme in Korean hip hop and therefore makes visible a key difference between Korean and English-language hip hop. Linguist Im Jae-hyun examines the public perception of hip hop in Korea through a linguistic analysis of three televised conversations concerned with questions of identity among Korean hip hop performers. This discussion of an "an idol rapper's identity negotiation, rappers' characterization of the aggressive aspects of rap battles, and the dual identity of a rapper who is also a teacher" guides the reader to more deeply consider the performance of hip hop beyond its musical expressions. The article by sociologist Kim Pil Ho and ethnomusicologist Lee Wonseok about industrial hip hop and the group XXX, and Amos Farooqi's article about regional hip hop from Gwangju, both explain the function of power structures, barriers to success and pathways to fame in the Korean hip hop industry. Kim and Lee examine how XXX challenges the hip hop community in their discourse, for example in the group's stated refusal to appear on the hit rap survival show Show Me the Money. Although XXX repudiates this now-familiar Korean pathway to fame, they are also a case of yeoksuip-a re-import that gained traction in Korea based on recognition abroad-and, as detailed by Kim and Lee, they have strategically used governmental support and the power of their well-connected label in an effort to maintain their independence. Farooqi begins his article with a vignette featuring a member of XXX, and then proceeds to detail how Seoul's dominance of the Korean musical industry undercuts the viability of local hip hop scenes, demonstrating how this Seoul-centrism, in tandem with weak local support for hip hop, "leav[es] virtually no space for local artists and crews to find success within their respective localities". Farooqi's four-year, embedded ethnographic study with a collective from Gwangju demonstrates the depth of talent in Korea while also illustrating the effects of the agglomeration of power and legitimacy in the nation's capital. Finally, the article by ethnomusicologist Kim Iljung addresses the presence (or absence) of women in the Korean hip hop scene, before diving into a "comparative analysis of songs released after 2015, when misogynistic rhetoric and feminist discourse began to permeate Korean society". Kim's analysis of feminist or womanist tropes in hip hop lyrics over the past twenty years is paired with an 
interview with female rapper Sleeq that challenges male-centrism in Korean hip hop.

It is the sound of hip hop that continues to supply the underground prideminoritarian, regional, female-that at times asserts a dissonant power in Korea, challenging the capitalist success stories of K-pop and its Seoul-centred universe in the smartphone era. The self-crafted lyrics of this dissonant power, with their reflection of contemporary issues in Korean society and their performative voicing of positions in marginalized venues, are the focus of this special issue. We, the editors, have attempted to select papers that pay homage to the spirit of hip hop, which has always set a benchmark of stylistic, musical and rhetorical innovations for the expression of social minorities.

\section{References}

Bauer, J. 1948. "Truman and Executive Order 9981: Idealistic Pragmatic, or Shrewd Politician?" Harry S. Truman Library. https://www.trumanlibrary.gov/education/ lesson-plans/truman-and-executive-order-9981-idealistic-pragmatic-or-shrewdpolitician (accessed 3 February 2020).

Cheng, Sealing. 2010. On the Move for Love: Migrant Entertainers and the U.S. Military in South Korea. Philadelphia: University of Pennsylvania Press. https://doi.org/10.9783/ 9780812206920

Cho, Grace. 2008. Haunting the Korean Diaspora: Shame, Secrecy, and the Forgotten War. Minneapolis: University of Minnesota Press.

Constante, Agnes. 2017. “25 Years After LA Riots, Koreatown Finds Strength in ‘Saigu' Legacy”. NBC News, 25 April. https://www.nbcnews.com/news/asian-america/25-years-afterla-riots-koreatown-finds-strength-saigu-legacy-n749081.

Em, Henry. 2013. The Great Enterprise: Sovereignty and Historiography in Modern Korea. Durham, NC: Duke University Press. https://doi.org/10.1215/9780822395928

Freeland, Jim and Jim Lea. 1971. "GIT: Key to Racial Equality". Pacific Stars and Stripes, 16 July 1971, https://starsandstripes.newspaperarchive.com/pacific-stars-and-stripes/ 1971-07-16/page-24 (User ID required for access).

Kim, Nadia Y. 2008. Imperial Citizens: Koreans and Race from Seoul to LA. Redwood City, CA: Stanford University Press.

Lea, Jim and Len Brown. 1971. "GIT: Key to Racial Equality". Pacific Stars and Stripes, 24 October. https://starsandstripes.newspaperarchive.com/pacific-stars-and-stripes/ 1971-10-24/page-11/.

Lee, Jin-kyung. 2010. Service Economies: Militarism, Sex Work, and Migrant Labor in South Korea. Minneapolis: University of Minnesota Press.

Lee, Nayoung. 2018. "Un/Forgettable Histories of US Camptown Prostitution in South Korea: Women's Experiences of Sexual Labor and Government Policies". Sexualities 21/5-6: 751-75. https://doi.org/10.1177/1363460716688683

Lie, John. 1995. "The Transformation of Sexual Work in 20th-Century Korea". Gender and Society 9/3: 310-27. https://doi.org/10.1177/089124395009003004

Maliangkay, Roald. 2006. "Supporting Our Boys: American Military Entertainment and Korean Pop Music in the 1950s and Early 1960s". In Korean Pop Music: Riding the Wave, edited by Keith Howard, 21-33. Kent: Global Oriental.

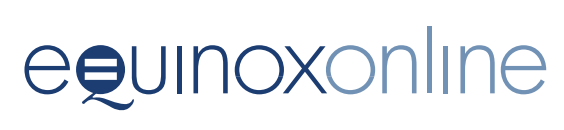


— 2011. "Koreans Performing for Foreign Troops: The Occidentalism of the C.M.C. and K.P.K.". East Asian History 37: 59-72.

— 2014. "The Popularity of Individualism: The Seo Taiji Phenomenon in the 1990s". In The Korean Popular Culture Reader, edited by Kyung Hyun Kim and Youngmin Choe, 296-313. Durham, NC: Duke University Press.

Park, Jeongmi. 2019. "Liberation or Purification? Prostitution, Women's Movement, and Nation Building in South Korea under US Military Occupation, 1945-1948". Sexualities 22/7-8: 1053-70. https://doi.org/10.1177/1363460718782968

Shin, Hyunjoon and Pilho Kim. 2014. "Birth, Death, and Resurrection of Group Sound Rock". In The Korean Popular Culture Reader, edited by Hyun-kyung Kim and Youngmin Choe, 275-95. Durham, NC: Duke University Press. https://doi.org/ 10.1215/9780822377566-017

Yi, Yong-u. 2005. "Miguk keurop seo hunryeon bateun daejung eumak" ["Popular Music Trained in American Military Clubs"]. Hankyoreh, 6 July 2005, http://www.hani. co.kr/arti/culture/culture_general/47952.html.

Yoon, In-jin. 2007. On My Own: Korean Businesses and Race Relations in America. Chicago: University of Chicago Press. 